\title{
EL FUNCIONAMIENTO DE LAS TECNOLOGÍAS \\ DE LA IMAGEN EN LA CREACIÓN DE IMAGINARIOS NORMATIVOS
}

\author{
Garazi Erdaide Cervigón \\ Universidad del País Vasco / Euskal Herriko Unibertsitatea. Doctorado en Investigación y Creación \\ en Arte
}

\section{Resumen}

En el presente artículo se analizan las tecnologías de la imagen como transmisoras de subjetividades sociales, poniendo el énfasis en la no neutralidad de los dispositivos fotográficos. Se ha examinado la tecnología fotográfica y su actual desarrollo tecnológico, a través del proyecto Colour Balance de Lorna Roth y de diferentes aplicaciones móviles relacionadas con la imagen, con el objetivo de estudiar su influencia en la creación de imaginarios colectivos dominantes. La observación de diferentes estudios que vinculan las tecnologías de la imagen con la construcción racializada nos lleva a afirmar que las diversas tecnologías de la imagen no solo generan lo normativo, sino que lo naturalizan. De esta manera, los nuevos dispositivos tecnológicos de creación, edición, visualización y distribución de imágenes contribuyen a la continuidad de miradas normativas del mundo. Se ha explorado el proyecto Humanae de Angélica Dass, considerando que la reflexión desde el ámbito artístico en torno a las relaciones de los dispositivos y las dinámicas sociales posibilita la toma de decisiones conscientes en la práctica artística así como la creación de nuevos imaginarios.

\section{Palabras-clave: DISPOSITIVOS FOTOGRÁFICOS; DINÁMICAS SOCIALES; VISUALIDAD; RACIALIDAD; IMAGINARIO COLECTIVO}

\section{THE WORKING OF IMAGING TECHNOLOGIES IN THE CREATION OF NORMATIVES IMAGININGS}

\section{Abstract}

In this article, imaging technologies as transmitters of social subjectivities are analysed, with an emphasis on the non-neutrality of photographic devices. It has examined photographic technology and its current technological development, through Lorna Roth's project Colur Balance and different mobile applications related to the image, in order to study his influence on the creation of dominant collective imaginings. The reflection through several studies that link imaging technologies with racialized construction its leads us to affirm that the different imaging technologies not only generate the norm but they naturalise them too. In this way, new technological devices of creation, editing, visualization and image distribution contribute to the continuity of normative visions of the world. Angélica Dass's project Humanae has been examined, from the point of view of art around device's relationships and social dynamics enables making conscious decisions on artistic practice as well as the creation of new imaginary.

\section{Keywords: PHOTOGRAPHIC DEVICES; SOCIAL DYNAMICS; VISUALITY; RACIALITY; COLLECTIVE IMAGINING}

\footnotetext{
Erdaide Cervigón. Garazi. 2016. "El funcionamiento de las tecnologías de la imagen en la creación de imaginarios normativos". AusArt 4(2): 67-81 DOI: 10.1387/ausart.17119
}

\section{AUSART}




\section{INTRODUCCIÓN}

"Las técnicas, los artificios, los dispositivos que utiliza el artista para concebir, construir y exhibir sus trabajos no son sólo herramientas inertes, ni mediaciones inocentes, indiferentes a los resultados, que se podrían sustituir por cualquier otras. Ellas están cargadas de conceptos, tienen historia, derivan de condiciones productivas bastante específicas"

(Machado 2004, 87).

Existe una clara relación entre las imágenes fotográficas y la construcción de miradas sobre el mundo. Esta relación no solamente deriva de las diferencias sobre qué personas generan las imágenes, qué personas las ven y qué personas son vistas y categorizadas en ellas (Haraway 1991), sino también, por lo que esas imágenes representan en tanto que construcciones. Tal como expone Rose, "La imaginería visual nunca es inocente; está siempre construida a través de varias prácticas, tecnologías y saberes"1. (Rose 2016, 23). Por ello, cabe preguntarse qué relaciones existen entre las tecnologías de la imagen y las dinámicas sociales, de qué manera los dispositivos fotográficos crean puntos de vista y qué tipo de conocimiento generan.

Así, en este artículo nos centramos en la reflexión sobre los dispositivos tecnológicos como herramientas con las que se crean, estructuran y muestran las imágenes fotográficas, no para obviar las dimensiones políticas y sociales en las que se producen e interpretan las imágenes sino para deconstruir de qué maneras y por qué medios los dispositivos repercuten en esas dimensiones.

Las significaciones derivadas de las imágenes fotográficas no son un mero producto de la persona que crea la imagen, ni de la imagen misma, ni de la interpretación y construcción de la persona receptora. Los discursos tecnológicos influyen en la misma composición de las imágenes y ejercen también relaciones de poder; podríamos decir que estos discursos atraviesan las imágenes. A su vez, las tecnologías de la imagen surgen de una visión del mundo muy concreta, en un contexto determinado por el cual son influidas en su creación. De manera que existe una clara interdependencia entre tecnología y dinámica social. 


\section{LA NO NEUTRALIDAD DE LOS DISPOSITIVOS FOTOGRÁFICOS: EL PROYECTO COLOUR BALANCE}

En su texto ¿Tienen política los artefactos? Winner sugiere que prestemos atención no sólo a los usos de las tecnologías que privilegian a unas personas sobre otras, sino a las características de los objetos técnicos y el significado de tales características (Winner [1983] 1985). Es decir, reflexiona sobre las cualidades políticas insertadas en las tecnologías. Investigando, por una parte, los objetivos concretos que están detrás de la creación y aplicación de un sistema técnico ${ }^{2}-\mathrm{y}$ los efectos sociales que estos objetivos concretos ejercen sobre la población-y por otro lado, las condiciones sociales que permiten la creación de dispositivos tecnológicos. Además, expone diversos argumentos en torno a si han de mantenerse o no las mismas condiciones que han posibilitado la creación de una determinada tecnología para la efectividad y perdurabilidad de la misma. En otros términos, si bien es cierto que algunos dispositivos tecnológicos son creados con objetivos específicos que determinan relaciones sociales, todos nacen de determinadas formas de ver el mundo y por tanto, reproducen miradas normativas sobre él.

La fotografía, en concreto, nace en medio de un siglo en el que se están dando los últimos pasos de la expansión colonialista (Blanco 1998). Se inserta bajo el modelo positivista del siglo XIX y su utilización por parte de la ciencia como técnica capaz de reproducir el mundo natural, de manera verdadera y objetiva ha conllevado miradas de lo normativo de las que aún hoy en día estamos inmersos ${ }^{3}$. Algunos valores que se gestaron en ese inicio de la fotografía podemos hoy analizarlos en los dispositivos de imagen de control y vigilancia.

"La fotografía era una manifestación de la sensibilidad tecnocientífica decimonónica y esparcía a lo largo del siglo XX los valores de esa sensibilidad. Así, la experiencia propiciada por la fotografía se emparentaba tanto con la mirada empírica del positivismo como con la actitud apropiacionista del capitalismo colonial".

(Fontcuberta [1984] 2003, 9)

Es en este contexto en el que nace el dispositivo fotográfico y es este dispositivo - creado desde una visión particular del mundo- el que contribuye a crear y perpetuar una forma de configurar el mismo. 
El proyecto Colour Balance de Lorna Roth (2009) es un claro ejemplo de cómo las tecnologías son creadas bajo determinadas ideologías y de cómo perpetúan miradas normativas. En esta extensa investigación sobre las representaciones del color, Roth analiza cómo los colores de la piel están insertos en los productos de consumo y se difunden a través de los mass media ${ }^{4}$.
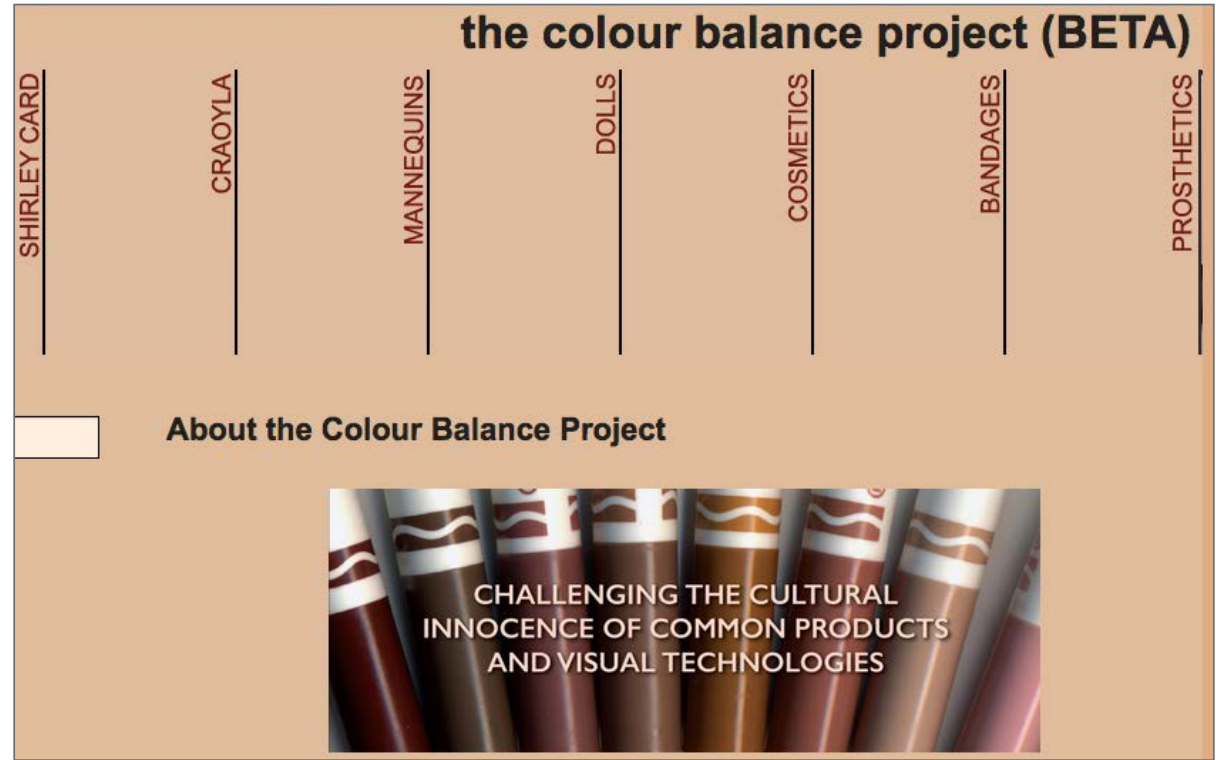

Fig.1: Imagen de la página web del proyecto Colour Balance de Lorna Roth.

Colour Balance, investigación que está actualmente en proceso, se va formando a través de distintos proyectos concretos en torno al color de piel como construcción. Cada proyecto pone el foco de atención en productos aparentemente inocentes para ver su relación con la construcción racial, a saber: cámaras y películas químicas, juguetes, maniquíes, cosmética y productos de belleza, pinturas, tiritas y prótesis, que entre otros analizados, construyen una mirada sobre el color desde la industria tecnológica. En efecto, estos productos no son inocentes y tampoco son neutrales. Han sido construidos desde la blancura como norma, como ideal de color de piel, quedando así estandarizada una gama de color concreta que ha sido y es usada como referencia a la hora de hablar del color "carne"5. 
En el caso específico del proyecto en el que analizan los dispositivos de creación de imágenes fotográficas y su relación con la racialidad, Shirley $\mathrm{Card}^{6}$, Roth toma el estándar de color de las tarjetas Shirley como punto de partida para ir analizando la tecnología fotográfica analógica y su evolución digital. El balance de color o equilibrio de color de una película fotográfica es "un ajuste de una película de color determinada, bajo la cual reproduce con precisión los colores del sujeto" (Langford 2007, 345). Roth explica cómo las tarjetas Shirley, en las que aparecen modelos caucásicas fueron la referencia que tenían de color los laboratorios fotográficos analógicos de Norte América hasta hace relativamente pocos años (Roth 2009).

Que los colores de las fotografías se basen solamente en los tonos de piel más claros implica tomar como norma "la blanquitud" y establecer, por lo tanto, lo que es "normal". Esta decisión de tomar tonos de piel más claros como ideal internacional en la industria del revelado químico supone que la gente con tonos de piel más oscuros no salgan bien representados en las imágenes fotográficas. La imaginería que se deriva de estas tecnologías de representación conduce a la invisibilización de una amplia gama de colores. Los colores más oscuros, que eran, por tanto, más difíciles de reproducir al tomar esos tonos claros como estándar de revelado, se relacionan con desviaciones de la norma (Roth 2009, 117).

Aunque existen problemas inherentes a las tecnologías, como por ejemplo la dificultad de combinar diversos tonos de color en la misma imagen debido a las emulsiones químicas o a la amplitud de rango dinámico en el caso digital (Roth 2009, 115) y a pesar de que la industria fotográfica, la televisiva y otras industrias de diversos productos han ido ampliando el espectro de colores para dar cabida a más consumidores, seguimos apreciando cómo muchos de los productos generados siguen estandarizando los colores más claros como ideales de color, tendencia que vemos por ejemplo, en los productos aclarantes de la piel $^{7}$.

Una de las preguntas fundamentales que se hace Roth en este proyecto es, ¿qué tipo de conocimiento sobre el color de la piel humana en forma de imaginería racial están construyendo y defendiendo los fabricantes a través de la comercialización de sus productos "presuntamente inocentes"? (Roth 2009, 116). E introduce el concepto de "equidad cognitiva"8, que se va desplegando en el conjunto de los proyectos que forman Colour balance y que supone la creación de una amplia gama de colores en los productos comunes y en las tecnologías visuales fomentando la equidad cultural y racial (Roth 2009, 127). 
Ahora bien, ¿han cambiado con las nuevas tecnologías los estándares sobre los que se asientan ciertos conceptos como, por ejemplo, el de belleza? ¿Qué suponen las nuevas tecnologías en la construcción de imaginarios? ¿Cómo relacionan estos dispositivos recientes lo técnico y lo social?

\section{CREACIÓN, EDICIÓN Y DISTRIBUCIÓN DE IMÁGENES DESDE APLICACIONES MÓVILES: LA BELLEZA EN LAS APPS}

"Me gusta pensar la técnica como un lenguaje, como el lenguaje que hablan entre sí los artefactos"

(Brea 2002, 113).

Cada vez un mayor número de personas acceden a aplicaciones tecnológicas y se relacionan con ellas en su día a día. Estas tecnologías entendidas como bienes de consumo afectan por lo tanto, actualmente, a más personas. Cabe preguntarse entonces, en qué nivel de conocimiento operan las personas usuarias $^{9}$ frente a estas tecnologías. ¿Entienden la construcción social que supone? ¿Perciben la no inocencia de los medios técnicos que usan continuamente?. Tal y como expone Francisco García $(2006,4)$ :

"Las sociedades humanas de una forma consciente o inconsciente privilegian, (...) unas tecnologías sobre otras, y al inclinarse por unas están también definiendo su forma de comportarse en el mundo, su forma de trabajar, de viajar, de vivir, de comunicarse, en definitiva de ser".

Este acceso masivo a nuevos dispositivos de imagen, como por ejemplo a la telefonía móvil -que entre otras de sus funciones principales está la de fotografiar-, plantea retos sobre la globalización de miradas derivadas de los mismos. A pesar de que las aplicaciones que forman parte esencial de estos dispositivos son consumidas a nivel global, las industrias tecnológicas encargadas de su creación trabajan bajo los mismos cánones. La operatividad del mercado con alcance global supone que los sujetos sean vaciados de sus significantes individuales (Lash y Urry 1998). 
Algunos intentos de aplicar miradas más diversas a las imágenes de las aplicaciones móviles han sido bastante polémicas. Pongamos por ejemplo, la última actualización de software ${ }^{10}$ que en 2015, introdujo Apple para modificar los emoticons o emojis. Estos "emoticonos" o "caritas"11 son expresiones faciales con las que muchas personas han empezado a comunicarse en sustituto o como ampliación de la utilización de la palabra. Los emoticonos que empezaron siendo textuales — signos de puntuación, que unidos aludían esquemáticamente a expresiones faciales - han derivado en imágenes -en pictogramas de color cada vez más extensos- que actualmente son creados y regulados por Unicode Consortium. En las diferentes declaraciones que realiza Unicode Consortium en torno a la construcción de emoticonos de género, raza y orientación sexual aparece frecuentemente la palabra neutral para designarlos (Davis \& Edberg 2015).

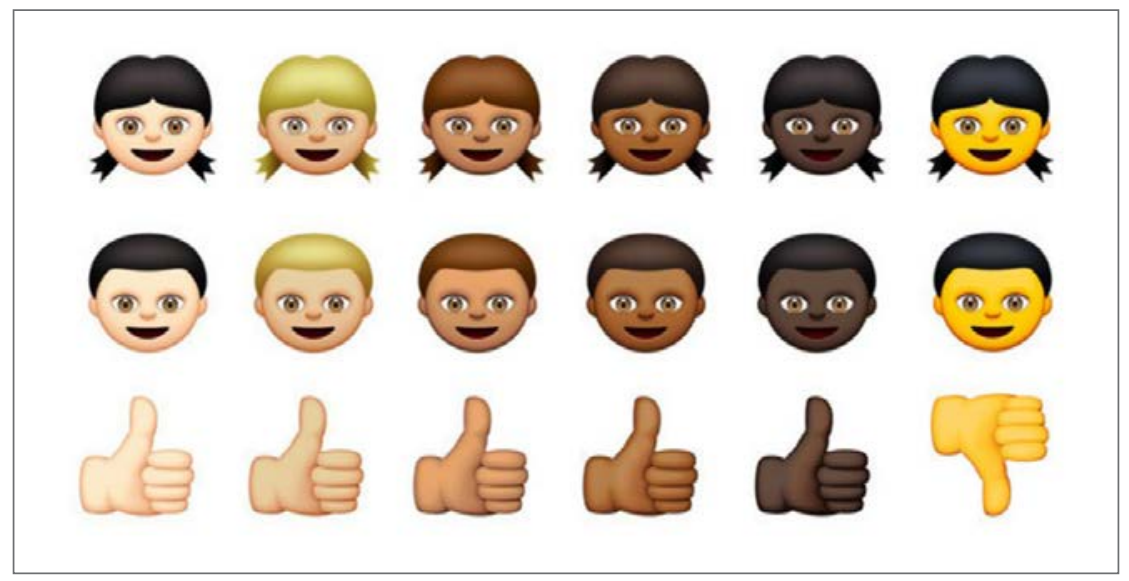

Fig.2: Imagen de la página web de Apple. http://www.applesfera.com/curiosidades/son-racistas-losnuevos-emojis-de-apple-aviso-de-spoiler-no

Teniendo en cuenta proyectos como Colour Balance, expuesto anteriormente, cabe preguntarnos si estas aplicaciones - con las mucha gente se comunica a diario, como por ejemplo la llamada WhatsApp — en las que se están ampliando las gamas de color en los emoticonos suponen un verdadero avance en la deconstrucción racializada de las tecnologías. Si atendemos a los demás emojis vemos cómo se repiten visiones normativas de género, por ejemplo, en la princesa o en la novia.

Las afirmaciones de Apple y de Unicode Consortium sobre la neutralidad de los emoticonos a la hora de presentar y representar modelos familiares o gamas 
de colores de piel, parecen acercarse a los argumentos por los que diversos autores señalan que la tecnología es neutral (Sampietro 2016, 65). Ejemplos recientes, como algunos de los emoticonos de la aplicación Snapchat han generado igualmente controversia, siendo en muchos casos retirados de la aplicación por demandas de los usuarios ${ }^{12}$. Como indica Francis, entre estos emoticonos parece entreverse el usuario ideal, el modelo normativo de persona, entre los que no tiene cabida por ejemplo la enfermedad o la diversidad funcional (2015).

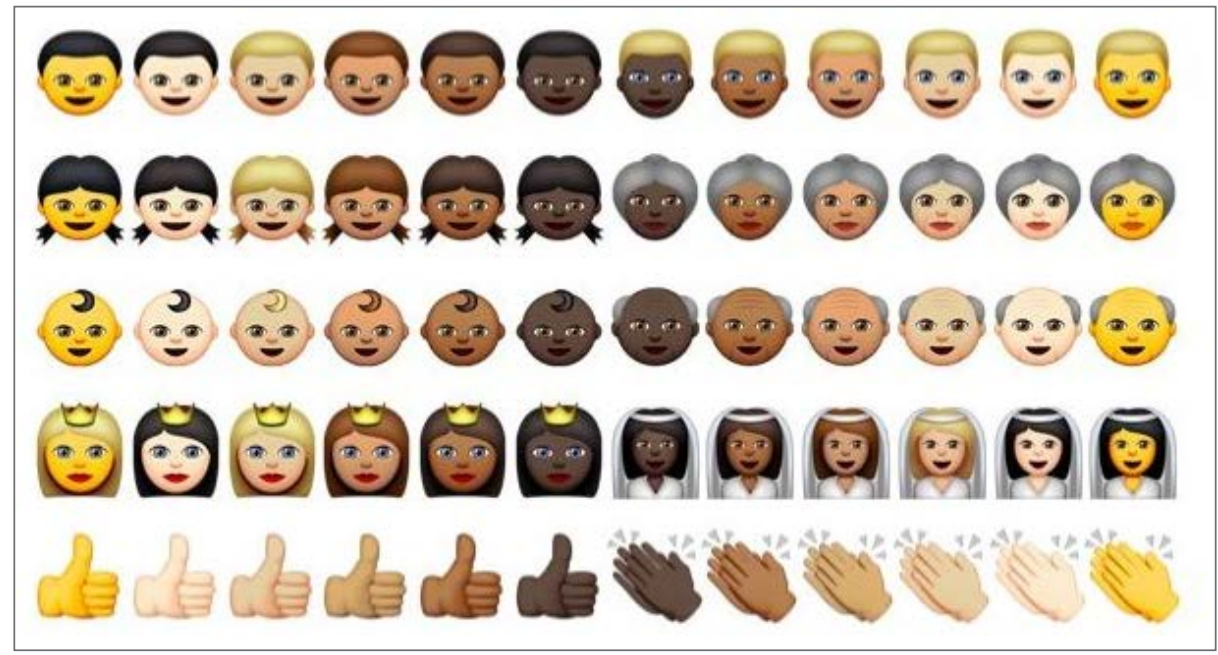

Fig.2: Imagen de emojis de WhachsApp. http://www.adsIzone.net/2015/06/30/ya-puedes-enviar-y-recibir-los-nuevos-emojis-multirraciales-con-whatsapp-para-android/

Este ideal de persona que la tecnología parece propiciar y privilegiar puede verse también reflejado en otras aplicaciones relacionadas con la fotografía. Entre estas nuevas aplicaciones que sirven para crear, editar y difundir imágenes fotográficas por medio de la telefonía móvil - generalmente por medio de otras aplicaciones de comunicación que usan Internet en esta telefoníadestacan las funciones que permiten editar las imágenes para hacerlas más bellas. El ideal de belleza sobre el que se instauran estos programas de retoque digital es el de la mujer blanca, europea y de clase media. Un ejemplo son las aplicaciones Make Me Asian —hazme asiático- y Make Me Indian - hazme indio - que creadas hace un par de años, permitían a las personas usuarias usar filtros de pigmentación de piel, modificaciones en los ojos, aplicación de pinturas estereotipadas e incluso el uso disfraces como por ejemplo, el de convertirte en un persona recién salida de Auschwitz. Tras diversas 
protestas, Google ha retirado estas aplicaciones de su tienda online ${ }^{13}$. Otras aplicaciones, sin embargo, como Make me a girl siguen vigentes en la tienda de aplicaciones de Google ${ }^{14}$.

En muchas de estas aplicaciones, entre las opciones creativas de "mejora" de imagen, se incluyen el blanqueamiento de piel, el adelgazamiento del cuerpo o el agrandamiento de los ojos. Además, incluso cuando el filtro a aplicar lleva otro nombre como brillo o suavizar, nombres que no hacen referencia a estas modificaciones de imagen anteriormente citadas, promueven los mismos ideales. Esto se hace evidente en las imágenes que publicitan estas aplicaciones, en las que muchas veces basan su mejora en el aclarado de la piel.

Estas aplicaciones perpetúan las construcciones desigualitarias y continúan con las visiones normativas de género, clase y raza que han heredado de tecnologías anteriores.

De modo que, desde la investigación artística, se hace evidente la insistencia en reflexionar sobre la no naturalización de las tecnologías que se usan en las prácticas artísticas. "Si existe ahora una discusión inevitable en el círculo de artistas que experimentan con dispositivos o procesos tecnológicos, esa discusión es ciertamente la que respecto a la propia naturaleza de la intervención artística en una época marcada por el tecnocentrismo" (Machado 2000, 18).

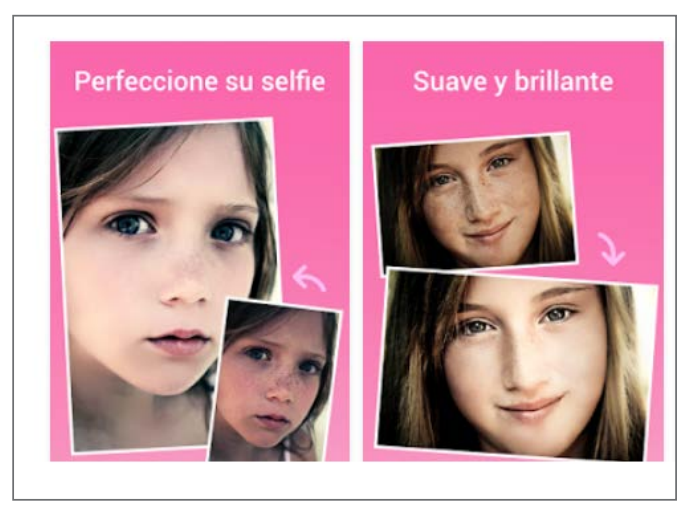

Fig.3: Imagen de la publicidad de la aplicación Beauy Camera https://play.google.com/store/apps/details?id=com. northpark.beautycamera [Acceso 28.09.2016]

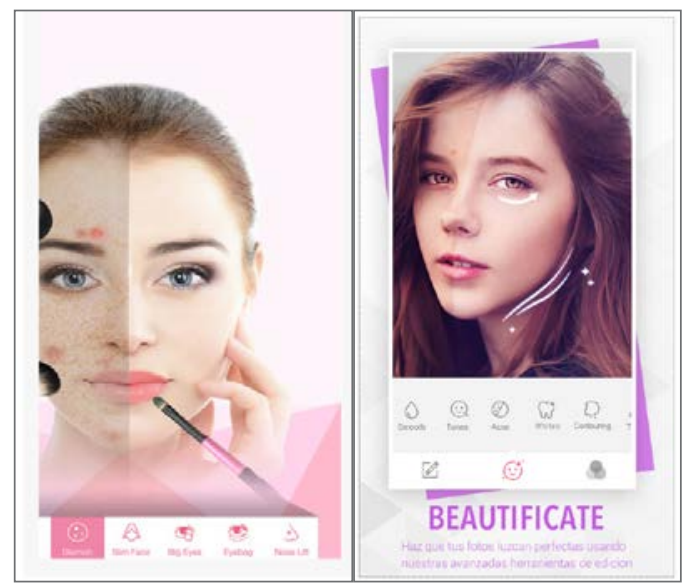

Fig.3 y 4: Imagen de la publicidad de las aplicaciones: InstaBeauty (izquierda) https://itunes.apple.com/es/app/ instabeauty-nice-camera-image/id599534650 y BeautyPlus (derecha) https://play.google.com/store/apps/detaiIs?id=com.commsource .beautyplus [Consultadas ambas 28.09.2016] 


\section{PRÁCTICAS ARTÍSTICAS Y TECNOLOGÍAS DE LA IMAGEN: EL PROYECTO HUMANAE}

Pensar la imagen fotográfica desde el ámbito artístico supone cuestionar la propia génesis de la imagen, su composición, el contenido inmerso en ella, los modos de producción, los de recepción, así como el contexto socio-político en el que se desenvuelve. Preguntarnos sobre las relaciones que se ponen en marcha al sacar la cámara, al mirar por el objetivo y al disparar. $\mathrm{O}$ al no disparar. Porque como propone Azoulay, el acontecimiento fotográfico no implica exclusivamente que haya imagen fotográfica resultante $(2011,74)$. También supone reflexionar sobre las condiciones tecnológicas que envuelven la práctica. Condiciones que repercuten en la creación de tecnologías mientras que, de igual manera, los efectos que esas tecnologías repercuten en las condiciones.

El proyecto Humanae ${ }^{15}$ de Angélica Dass parece subvertir las miradas racializadas desde la práctica artística en la que propone nuevas maneras de cuestionar los binomios blanco y negro asociados al color de la piel. En este caso, visualiza la imposibilidad de hablar de los cuatro tonos de piel asociados a raza, a saber: blanco, negro, rojo y amarillo, ${ }^{16}$ fotografiando a personas y creando un inventario cromático a partir de la combinación de colores Pantone ${ }^{\circledR}$. Su proyecto consiste en realizar retratos cuyo fondo tiñe del tono exacto del Pantone ${ }^{\circledR}$ que le corresponde al extraer de una muestra de 11x11 píxeles de la nariz de las personas retratadas (Dass 2016, min. 4:23). Tal y como Dass afirma, incluso este color no es el único que representa a la persona retratada ya que al tomar la muestra de la nariz el color puede cambiar bajo diferentes condiciones (si se ha tomado el sol, si la persona está resfriada, etc.). El uso de estas guías es, según Dass, una manera de desplazar la visión "inocente" del color y asegurarse de que los colores primarios tienen igual importancia que los colores mezclados. Además su horizontalidad y el mantenimiento del formato y de la técnica de extracción del color del fondo permite que esta taxonomía fotográfica sea ética ${ }^{17}$.

Con este proyecto Dass, pone en relación las tecnologías de la imagen y los efectos que las mismas tienen sobre la creación de subjetividades, explorando la identidad a través del color. Sus fotografías no son sólo contenedoras de retratos individuales, son visualizaciones de reflexiones sobre la construcción de categorías, involucrando más aspectos de la identidad que la racialidad. 
Las personas retratadas en Humanae, son voluntarias que se han ido involucrando en el proyecto a través de las redes sociales. Siendo éste un proyecto que se ha ido compartiendo en Internet, sus efectos se han ido expandiendo y han sido usados en diversas actividades. A nivel pedagógico, se han impartido talleres que toman el proyecto Humanae como base sobre el que repensar tanto con niños y niñas como con adultos la racialidad ligada al color. Dass no obstante, está enseñando en diferentes cursos cómo mezclar colores para encontrar nuestro propio color de piel, deconstruyendo lo asociado al color "carne".

\section{CONCLUSIONES Y NUEVAS LÍNEAS DE DEBATE}

Pensar las imágenes fotográficas en términos tecnológicos nos ha llevado a ver bajo qué condiciones, en qué ámbitos y con qué intereses comerciales e ideológicos se crean estas tecnologías y, asimismo, los efectos sociales que las propias tecnologías generan.

Consideramos que entender la fotografía como una práctica social nos lleva a analizarla desde la interrelación de sus significaciones, cuestionándonos no sólo lo que la imagen resultante propone a nivel composicional, lo que muestra y los efectos que tiene eso que muestra. Sino verla desde una perspectiva mixta (Rose 2016), que englobe cuestionamientos sobre quién hace la imagen, cómo la hace, dónde está realizada, de qué tecnologías depende, qué relaciones establece con lo fotografiado, quién la recibe, en qué contexto, bajo qué circunstancias, qué conocimientos pone en marcha, cuales excluye, etc.

Es desde esta perspectiva desde la que se ha analizado cómo las tecnologías de la imagen son transmisoras de subjetividades sociales, entendiendo que estas tecnologías conviven y se retroalimentan con las dinámicas sociales. Siendo esto así, hemos podido apreciar la no neutralidad y la no inocencia de los dispositivos fotográficos. Tanto en el caso específico de Shirley Card - parte del proyecto Colour Balance- como de la evolución de la fotografía digital, específicamente en el uso de las aplicaciones móviles de edición de fotografía se ha observado cómo estas tecnologías que nacen bajo una ideología concreta generan desde esa ideología posiciones dominantes. En definitiva, no sólo generan lo normativo sino que lo naturalizan en sus discursos. De 
esta aproximación deriva cómo la fotografía tanto analógica como digital crea imaginarios colectivos dominantes.

Entendiendo que las prácticas artísticas pueden subvertir y subvierten las miradas normalizadas, se ha analizado el trabajo Humanae de Angélica Dass para ver en su propuesta reflexiones visuales cercanas a las analizadas en este artículo anteriormente. En este caso, no hemos hecho hincapié en los debates en torno a en qué medida la persona artista ha de conocer el medio, bien subvirtiendo las normas de la máquina, bien rehaciendo a nivel programático la máquina, bien creando sus propios dispositivos. Lo que se ha pretendido es ver de qué manera este trabajo artístico se resiste a la construcción normativizada del mundo creando nuevos imaginarios.

Queda por delante, el análisis de otros trabajos tanto teóricos como prácticos que reúnan lo que Roth ha definido como "equidad cognitiva" e inventar nuevos métodos visuales que permitan entrelazar todos los aspectos de la reflexión fotográfica.

\section{Referencias}

Azoulay, Ariella. 2011. "Photography". Mafte'akh, Lexical Review of Political Thought 2: 65-80

Blanco Aguinaga, Carlos. 1998. Sobre el modernismo, desde la periferia. Granada: Comares

Brea, José Luis. 2002. La era postmedia: Acción comunicativa, prácticas (post)artísticas y dispositivos neomediales. Salamanca: Centro de Arte de Salamanca. http://medialab-prado. es/mmedia/10509/view

Caro, Robert A. 1974. The power broker: Robert Moses and the fall of New York. New York: Random House

Caswell, Estelle, Joe Posner. 2015. "Color film was built for white people. Here's what it did to dark skin”. Vídeo de Youtube. 4:38. Publicado 18 sept. https://www.youtube.com/watch?$\mathrm{v}=\mathrm{d} 16 \mathrm{LNHIEJZS}$

Couchot, Edmond. 1998. La technologie dans l'art: De la photographie à la réalité virtuelle. Nîmes: Jacqueline Chambon

Dass, Angélica. 2016. "The beauty of human skin in every color". Videoconferencia TED, 11:27. Publicada en feb. https://www.ted.com/talks/angelica_dass_the_beauty_of_human_skin_ in_every_color

Davis, Mark \& Peter Edberg, eds. 2016. Unicode Emoji. Unicode Technical Report \#51. Version 4.0, 22 nov. http://www.unicode.org/reports/tr51/\#Common_Additions

Flusser, Vilém. 2015. El universo de las imágenes técnicas: Elogio de la superficialidad. Traducción Julia Tomasini, introducción y notas Claudia Kozak. Buenos Aires: Caja Negra 
Fock, Stefanie. 2014. "Cuerpos, miradas y memorias fotográficas: Una (de)construcción de género y raza”. Trabajo fin de Máster, Univ. Granada. http://digibug.ugr.es/ handle/10481/34033

Fontcuberta, Joan, ed. (1984) 2003. Estética fotográfica. Barcelona: Gustavo Gili

Foster, Hal, ed. 1988. Vision and Visuality. Seattle: Bay Press

Francis, Hannah. 2015. “Apple's new 'diverse' emojis are not diverse enough". The Sydney Morning Herald. 24 feb. http://www.smh.com.au/action/printArticle?id=66584864

García García, Francisco. 2006. “De la convergencia tecnológica a la convergencia comunicativa en la educación y el progreso". Icono 14 4(1): 1-19. http://www.icono14.net/ojs/index. php/icono14/issue/view/Vol\%204\%20\%281\%29

Haraway, Donna. 1991. Simians, cyborgs, and women: The reinvention of Nature. London: Routledge

Langford, Michael J. (1965) 2007. Fotografía básica. Traducido por Pilar Onyós. Barcelona: Omega

Lash, Scott \& John Urry, eds. 1998. Economías de signos y espacios. Sobre el capitalismo de la posorganización. Traducción José Luis Etcheverry. Buenos Aires: Amorrortu

Machado Neto, Arlindo Ribeiro. 2000. "Repensando a Flusser y las imágenes técnicas". En El Paisaje Mediático: Sobre el desafío de las poéticas tecnológicas. Buenos aires: Libros del Rojas

- 2004. "Arte y medios: Aproximaciones y distinciones". La Puerta FBA 1: 84-93. http:// sedici.unlp.edu.ar/handle/10915/20001

Rose, Gillian. 2016. Visual methodologies: An introduction to researching with visual materials. London: Sage

Roth, Lorna. 2009. "Looking at Shirley, the ultimate norm: Colour balance, image technologies, and cognitive equity". Canadian Journal of Comunication 34(1): 111-36

Sampietro, Agnese. 2016. Emoticonos y emojis: Análisis de su historia, difusión y uso en la comunicación digital actual. Tesis doctoral, Univ. Valencia. http://roderic.uv.es/ handle/10550/53873

Winner, Langdon. (1983) 1985. “¿Tienen política los artefactos?”. Versión castellana de Mario Francisco Villa. Organización de Estados Iberoamericanos, Sala de lectura CTS+I. http:// www.oei.es/historico/salactsi/winner.htm

\section{Notas}

1 Traducción de Garazi Erdaide Cervigón. "Visual imagery is never innocent; it is always constructed through various practices, technologies and knowledges".

${ }^{2}$ Winner expone un ejemplo concreto que es clarificandor en cuanto a cómo ciertas tecnologías se crean desde un punto de vista particular que discrimina por cuestiones de sexo, género o raza - entendemos estos conceptos como construcciones no como cualidades naturales inherentes a los cuerpos-.

Todo el que haya viajado alguna vez por las autopistas americanas y se haya acostumbrado a la altura habitual de sus pasos elevados puede que encuentre algo anormal en 
los puentes sobre las avenidas de Long Island, en Nueva York. Muchos de esos pasos elevados son extraordinariamente bajos, hasta el punto de tener tan sólo nueve pies de altura en algunos lugares. Incluso aquellos que perciban esta peculiaridad estructural no estarían inclinados a otorgarle ningún significado especial. En nuestra forma habitual de observar cosas tales como carreteras y puentes, vemos los detalles de forma como inocuos, y raramente pensamos demasiado en ellos. Resulta, no obstante, que los cerca de doscientos pasos elevados de Long Island fueron deliberadamente diseñados así para obtener un determinado efecto social. Robert Moses, el gran constructor de carreteras, parques, puentes y otras obras públicas de Nueva York entre los años veinte y setenta, construyó estos pasos elevados de tal modo que fuera imposible la presencia de autobuses en sus avenidas. De acuerdo con las evidencias presentadas por Robert A. Caro en su biografía de Moses, las razones que el arquitecto ofrecía reflejaban su sesgo clasista y sus prejuicios raciales. Los blancos de las clases "ricas" y "medias acomodadas", como él los llamaba, propietarios de automóviles, podrían utilizar libremente los parques y playas de Long Island para su ocio y diversión. La gente menos favorecida y los negros, que normalmente utilizaban el transporte público, se mantendrían a distancia de dicha zona porque los autobuses de doce pies de altura no podrían transitar por los pasos elevados. Una consecuencia era la limitación del acceso de las minorías raciales y grupos sociales desfavorecidos a Jones Beach, el parque público más alabado de los que Moses construyó. Moses se aseguró de que los resultados de sus diseños fueran efectivos vetando poco después una propuesta de extensión del ferrocarril de Long Island hasta Jones Beach.

(Referido en Caro 1974).

${ }^{3}$ Véase el estudio realizado como Tesina Final de Máster por Stefanie Fock, en torno a la fotografía como tecnología de género y raza en la que se analiza la práctica fotográfica de Myra Greene (2014)

${ }^{4}$ Colour Balance, http://colourbalance.lornaroth.com/ [Acceso 28.09.2016]

${ }^{5}$ Esta expresión comúnmente usada al igual que la de color "piel", lleva a pensar las pieles en un único tono de color. Asimismo, el color nude que hace refencia al color del tono de piel -no usandose la expresión en plural, a saber, colores nude-ha sido usado en diferentes campañas de moda que, salvo alguna excepción, han tomado como referencia la piel de tonos más claros.

${ }^{6}$ Colour Balance, proyecto Shirley Card, http://colourbalance.lornaroth.com/projects/shirley-card/ [Acceso 28.09.2016]

${ }^{7}$ Existen numerosas marcas de cosméticos y alimentación que tienen entre su gama de productos, cremas, jabones y pastillas con las que aclarar el tono de piel. El lenguaje publicitario al que recurren relaciona la belleza y el status social y económico a las pieles más claras. Algunos ejemplos que han sido especialmente polémicos serían los de la marca senegalesa Khess Petch http://www.senenews.com/2012/09/20/khess-petch-cette-publicite-qui-choque_42086.html [Acceso 28.09.2016] o los de la compañía Tailandesa Seoul Secret https://www.seoulsecret.com/th/ [Acceso 28.09.2016].

${ }^{8}$ Traducción de Garazi Erdaide Cervigón. "Cognitive equity"

${ }^{9}$ Utilizamos el término usuario en relación a la reflexión de Flusser sobre el nivel de operatividad que el artista tiene frente a las máquinas con las que trabaja (2015).

${ }^{10}$ Actualización iOS 8.3 y OS X 10.10 .3 
${ }^{11}$ Para analizar con mayor profundidad véase la tesis doctoral de Sampietro, Agnese. Emoticonos y emojis: análisis de su historia, difusión y uso en la comunicación digital actual. (Tesis Doctoral, Universidad de Valencia, 2016)

12 http://www.xataka.com.co/aplicaciones/snapchat-elimina-uno-de-sus-filtros-tras-ser-acusada-de-racismo [Acceso 20.09.2016]

${ }^{13} \mathrm{http}: / /$ yosoyandroid.com/2013/01/google-saca-del-playstore-dos-aplicaciones-consideradas-racistas/ [Acceso 15.09.2016]

${ }^{14} \mathrm{https}$ ///play.google.com/store/apps/details?id=com.photoappszone.makemegirl\&hl=es_419 [Acceso 25.09.2016]

${ }^{15}$ http://humanae.tumblr.com/ [Acceso 29.09.2016]

${ }^{16}$ Véase la explicación que Angélica Dass da de su proyecto en el video de TED. En el minuto 4:07 afirma como esos cuatro colores han sido asociados a raza https://www.ted.com/ talks/angelica_dass_the_beauty_of_human_skin_in_every_color.

${ }^{17}$ http://humanae.tumblr.com/About 